\title{
A governança corporativa em empresas estatais brasileiras frente a Lei de Responsabilidade das Estatais (Lei no 13.303/2016)
}

Joaquim Rubens Fontes-Filho

Fundação Getúlio Vargas (FGV)

O objetivo deste artigo é alinhar argumentos e informações para avaliar a situação das empresas estatais no Brasil, em particular quanto aos limites para seu desenvolvimento com base nas práticas de governança corporativa. A implementação dos comandos da nova Lei de Responsabilidade das Estatais (Lei no 13.303/2016) trouxe perspectivas otimistas para o fortalecimento da governança dessas empresas, ampliando sua autonomia, a profissionalização da administração e a explicitação dos compromissos de consecução de objetivos de políticas públicas. Com base no referencial da teoria da agência e principal-principal, é descrita a situação das empresas estatais no Brasil nos vários entes federativos e elaborado o mapa das pressões e interesses dos stakeholders, com vistas a elencar potenciais desafios e exigências para o desenvolvimento das empresas estatais, segundo suas configurações de governança.

Palavras-chave: governança corporativa, empresa pública - Brasil

[Artigo recebido em 16 de abril de 2018. Aprovado em 8 de agosto de 2018.] 
La gobernanza corporativa en empresas estatales brasileñas frente a la Ley de Responsabilidad de las Estatales (Ley no 13.303 / 2016)

El objetivo de este artículo es alinear argumentos e informaciones para evaluar la situación de las empresas estatales en Brasil, en particular en cuanto a los límites para su desarrollo con base en las prácticas de gobierno corporativo. La implementación de los comandos de la nueva Ley de Responsabilidad de las Estatales (Ley no 13.303/2016) trajo perspectivas optimistas para el fortalecimiento de la gobernanza de esas empresas, ampliando su autonomía, la profesionalización de la administración y la explicitación de los compromisos de consecución de objetivos de políticas públicas. Con base en el referencial de la teoría de la agencia y principal-principal, se describe la situación de las empresas estatales en Brasil en los diversos entes federativos y se elabora el mapa de las presiones e intereses de los stakeholders, con miras a plantear potenciales desafíos y exigencias para el desarrollo de las empresas estatales, según sus configuraciones de gobierno corporativo.

Palabras clave: gobernanza corporativa, empresa pública - Brasil

\section{Corporate governance in Brazilian state-owned companies under the Law of State} Responsibility (Law 13303/2016)

This article aims to present arguments and information to evaluate the situation of stateowned enterprises (SOE) in Brazil, particularly regarding the limits to their development, based on their corporate governance practices. The implementation of the new State Enterprise Law (Law n. 13.303/2016) brought optimistic perspectives to strengthen the governance of these companies, increasing their autonomy, professionalization of administration and the specification of commitments to achieve public policy objectives. Based on the framework of the agency theory and the principal-principal theory, the situation of state-owned enterprises in Brazil owned by the various levels of the federation is described and a map of stakeholder pressures and interests is presented, with a view to identifying potential challenges and requirements for the development of SOEs according to their corporate governance configurations.

Keywords: corporate governance, public company - Brazil 


\section{Introdução}

A aprovação da Lei no 13.303, em junho de 2016 (BRASIL, 2016a), criou um novo marco legal para as empresas estatais no Brasil e buscou proporcionar condições para que essas empresas se tornassem mais orientadas a demandas do Estado que de grupos políticos situacionistas. Denominada também como Lei das Estatais, Lei de Responsabilidade das Estatais, ou Estatuto Jurídico das Empresas Estatais, a lei é organizada em três títulos, tratando o primeiro das questões de gestão e governança das empresas estatais; o segundo, das licitações e contratos celebrados por essas empresas; e o terceiro, das disposições finais e transitórias. A discussão deste artigo está delimitada às questões postas no Título I, posteriormente regulamentado pelo Decreto no 8.945/16 (BRASIL, 2016b).

O amplo debate que marcou a revisão do estatuto da Caixa Econômica Federal, no início de 2018, e a profunda revisão no estatuto da Petrobras tanto trouxeram à luz as motivações e argumentos para a revisão das regras de governança das estatais como também expuseram a relação umbilical dessas empresas com a conformação do modelo presidencialista de coalizão vigente no país, como identificado por Abranches (1988) há mais de três décadas.

As empresas estatais representam um importante mecanismo de participação estatal no domínio econômico em diversos países. Levantamento apresentado em 2013 mostrou que, entre as 2.000 maiores empresas globais, integrantes do ranking Forbes Global 2.000, as empresas de controle estatal representavam mais de $10 \%$ da amostra, e estavam presentes em 37 países, com vendas somadas de US\$ 3,6 trilhões em 2011, o equivalente a cerca de 6\% do PIB global (BüGE et al., 2013). Embora predominantes em países em desenvolvimento e orientados por um capitalismo de Estado, a presença de empresas estatais é significativa também em países europeus como Noruega, França, Grécia e Alemanha.

No Brasil, seja pelo volume dos ativos e importância econômica das empresas estatais, nos vários níveis federativos, seja por sua influência histórica na construção do modelo de desenvolvimento nacional, as empresas estatais têm tido uma expressiva influência nas dimensões sociais, econômicas e políticas. Sociais, pela geração de empregos e políticas de pessoal, em geral oferecendo condições acima dos padrões do mercado privado, funcionando como um direcionador; econômicas, pois representam fontes importantes de receitas para os governos pelos dividendos distribuídos, pelo poder de apoiar setores e programas de desenvolvimento, e pelos próprios investimentos que realizam; e políticas, por se qualificarem como atores de destaque das composições políticas e das barganhas na formação das coalizões de poder. 
Qual a necessidade e importância das empresas estatais para o desenvolvimento do Brasil? Para além da retórica ideológica, que estabelece uma polarização entre o Estado mínimo e o Leviatã hobbesiano, discutir as estruturas da administração indireta e, particularmente, das empresas públicas e sociedades de economia mista mostra-se um desafio necessário sob vários aspectos. Este artigo, contudo, passa ao largo dessa discussão, para focar na qualidade da governança e gestão dessas empresas, seguindo a premissa de que, uma vez instaladas, devem responder tanto pela efetividade na sua atuação como pelo zelo com a eficiência das operações, respeitando permanentemente sua razão de criação.

Ocorre, contudo, que tanto a efetividade como a eficiência são com frequência de difícil avaliação para as estatais, principalmente porque a maioria opera em condições únicas de falhas de mercado ou em ambientes de ausência de interesse econômico. Seguindo as definições correntes, eficiência direciona a adequada gestão dos recursos em relação às atividades, ou a competência para produzir resultados com o menor uso de recursos e esforços, enquanto efetividade remete à capacidade de atingir os resultados pretendidos, trazendo o efeito desejado (RossI; Dos SANTOS, 2016). Se a efetividade, ou efeito desejado, está sujeita às variações de interpretação no comando político ou da sociedade, a eficiência é prejudicada pelas falhas de governança, fragilidade no modelo meritocrático empresarial, e uso dos recursos da estatal para ações de políticas públicas descoladas de sua função precípua.

A empresa estatal é constituída como entidade da administração indireta, exatamente para ter mais liberdade de ação. Conceitualmente, isso permitiria também à estatal estar mais exposta a um sistema de avaliação empresarial, em que sua eficiência poderia ser mensurada ou mesmo comparada com aquela de outras empresas.

Este ensaio visa identificar e discutir os principais desafios para a atuação das empresas estatais, com base na configuração de sua governança corporativa, tendo como referência a nova Lei de Responsabilidade das Estatais. Nesse sentido, a governança das empresas estatais é analisada, utilizando a perspectiva das teorias da agência e principal-principal, com vistas a identificar a efetividade dos mecanismos internos e externos de controle frente às pressões que modelam sua atuação.

$\mathrm{Na}$ segunda seção, a seguir, é elaborado referencial sobre a governança corporativa, visando situá-la como uma arena de poder e disputa de interesses, do qual decorre a prevalência do tratamento do problema de agência entre acionistas e gestores, apontando às limitações desse enquadramento conceitual para um adequado direcionamento aos problemas de governança das empresas estatais, 
trazendo como alternativa teórica à perspectiva principal-principal. A seguir, é caracterizada a atuação da empresa estatal no Brasil, consolidando as limitadas informações disponíveis sobre o conjunto das estatais detidas pela União, pelos estados, pelo Distrito Federal e pelos municípios.

A quarta seção analisa os dilemas e desafios relacionados à governança das empresas estatais, ampliando o quadro principal-agente, em que a governança é eminentemente um problema de acionistas e investidores, para o mapa de forças e stakeholders predominantes, pelo qual é possível identificar as pressões que modelam e fiscalizam a atuação das administrações das empresas estatais. Por fim, a quinta seção busca consolidar os argumentos e discussões anteriores, para elencar potenciais desafios e exigências para o desenvolvimento das empresas estatais, em especial no que tange aos aspectos da governança.

\section{Governança corporativa e os múltiplos problemas de agência}

Uma breve revisão histórica dos eventos que orientaram o fortalecimento da governança corporativa no mundo permite evidenciar o problema de agência como basilar a esse movimento.

Os conflitos de agência na empresa moderna decorrem de uma separação entre a propriedade, dos acionistas, e o controle da empresa, nas mãos dos gestores, modelo predominante em contextos de propriedade pulverizada, mas pouco significativo quando a propriedade concentrada é majoritária. Nesse caso, o problema se desloca para a relação entre os principais (acionistas), quando o controlador pode realizar ações e escolhas que prejudiquem os interesses dos minoritários, qualificado na literatura como problema principal-principal, predominante no contexto das economias emergentes (Young et al., 2008).

São várias as definições para governança corporativa, mas o reexame da história mostra dois pontos ou problemas fundamentais: a coordenação entre proprietários na definição do uso e disposição da propriedade, e o monitoramento das atividades desempenhadas pelos agentes, responsáveis pela adequada gestão dos recursos para alcançar os fins ou objetivos desejados pelos proprietários. Se na empresa com propriedade dispersa o problema do free rider é significativo, a existência de controlador torna esse problema menos relevante, dada a possibilidade de captura e retorno dos benefícios do ativismo.

Por influência e interesse dos mercados anglo-saxões, e possivelmente o pioneirismo do primeiro código com diretrizes de boa governança emitido no Reino Unido em 1992, o debate e os estudos sobre a governança receberam uma forte orientação para o problema de agência. 
De fato, já na década de 1970 era visível a preocupação dos acionistas e investidores com o crescente poder obtido pelos executivos, avançando em ações e estratégias que mais os beneficiavam (self-dealing) que aos acionistas, explorando as assimetrias de informação e a elevada dispersão dos proprietários.

Nesse contexto, o problema central da governança corporativa se orientou para formas de evitar o oportunismo gerencial, assegurando que os gestores agissem sempre no melhor interesse dos acionistas. Como definido por Shleifer e Vishny (1997), "Governança corporativa lida com as maneiras pelas quais os fornecedores de recursos financeiros para as empresas se asseguram de obter um retorno sobre seus investimentos" ${ }^{11}$ (p.737, tradução nossa). A elaboração teórica do problema de agência por Jensen e Meckling (1976), relacionando o acionista (principal) aos gestores (agentes), consolidou a importância da adoção de mecanismos que limitassem o potencial de self-dealing dos gestores e oferecessem incentivos adequados para que buscassem maximizar os interesses dos acionistas.

Além dos instrumentos de monitoramento, bonding e incentivos propostos por Jensen e Meckling (1976), observações posteriores indicaram também a capacidade de diversos outros mecanismos, inclusive externos à empresa, de limitar ou modelar o comportamento dos gestores. Agrawal e Knoeber (1996) organizaram em um conjunto de sete mecanismos as propostas anteriores sobre mecanismos de controle, internos e externos, com potencial para reduzir os problemas de agência: (i) participação acionária dos executivos, atribuindo-lhes os benefícios e resultados da propriedade; (ii) participação elevada na propriedade de investidores institucionais, mais preparados e motivados para uma supervisão ativa; (iii) concentração das ações em um acionista ou grupo (blockholders), criando estímulos para as ações de monitoramento dos executivos; (iv) participação de conselheiros externos nos boards, para maior independência na supervisão da empresa; (v) uso de financiamentos e dívidas, por ampliar o monitoramento realizado pelos credores; (vi) o mercado de trabalho para os executivos, trazendo visibilidade e reputação às suas ações frente a outros potenciais contratantes; e (vii) o mercado de controle corporativo, que pode criar uma disciplina poderosa pela ameaça de aquisição de empresas ineficientes.

Quando avaliados esses mecanismos de controle para o Brasil, e certamente para a maioria dos países não submetidos à common law, diversos questionamentos emergem. No Brasil, a propriedade das empresas listadas na bolsa de valores é concentrada, em sua ampla maioria, com a propriedade direta das ações votantes detida por um acionista ou grupo, eventualmente unidos por acordo de acionistas.

\footnotetext{
1 "corporate governance deals with the ways in which suppliers of finance to corporations assure themselves of getting a return on their investment".
} 
Esse arranjo torna praticamente inexistente o mercado de controle corporativo, não tendo de fato ocorrido qualquer aquisição hostil em tempos recentes. A participação dos executivos na propriedade, detendo quantidade expressiva de ações e capacidade para influenciar os destinos da empresa, ainda é pouco significativa para representar uma ameaça aos controladores, e o uso de financiamentos e dívidas pelas empresas mostra-se frágil como mecanismo externo de controle.

A importância da difusão das boas práticas de governança corporativa não decorre apenas de sinalizações de investidores que aceitariam pagar um maior valor por empresa com boa governança - que, no Brasil, seria de até $22,9 \%$ a mais por ações de empresas com boas práticas de governança (MCKINSEY, 2000). Como registra o documento da OECD (2015, p. 3, tradução nossa), "A boa governança corporativa não é um fim em si mesma. É um meio para criar confiança no mercado e integridade nos negócios (grifo nosso), o que, por sua vez, é essencial para as empresas que precisam ter acesso a capital próprio para investimentos de longo prazo."2

Em um contexto de elevado risco de expropriação do minoritário, a confiança e a integridade dos negócios representam requisitos fundamentais à sua participação no mercado de capitais. Uma maior segurança ao pequeno acionista trazida por boas práticas de governança, garantindo seus direitos e ampliando o dever de transparência e prestação de contas de controladores e gestores, contribuirá para atrair os investimentos desses acionistas, gerando maior liquidez ao mercado bursátil e efeitos positivos sobre o preço das ações, o que irá estimular as empresas a ampliarem a captação de recursos nas bolsas de valores (CARVALHO, 2002).

Uma visão mais recente do problema de agência remete às diferenças entre os ambientes de propriedade difusa e concentrada. Dada a prevalência da empresa com controlador ou blockholder - tais como famílias, estado, outras empresas e investidores institucionais, a exemplo dos fundos de investimento, seguradoras e fundos de pensão -, diversos estudos vêm deslocando o problema fundamental da governança para a relação principal-principal, entre os próprios acionistas, ou mais propriamente entre acionistas controladores e minoritários (YouNG et al., 2008; JiAng; Peng, 2011; WARD; Filatotchev, 2010; EstWick, 2016). De fato, essa tensão entre acionistas exprime o potencial de expropriação dos minoritários pelos controladores, caracterizado pelo prêmio de controle. No Brasil, estudos anteriores mostraram que esse prêmio, medido pela diferença de valor das ações dos controladores frente às demais ações, chegou a ser o maior do mundo (DYCK; ZINGALES, 2004).

\footnotetext{
2 "Good corporate governance is not an end in itself. It is a means to create market confidence and business integrity (grifo nosso), which in turn is essential for companies that need access to equity capital for long term investment."
} 
Essa tensão nas relações entre os atores da governança exige perspectivas que ampliem o foco da díade principal-agente na governança e considerem as disputas de poder entre um conjunto mais amplo de atores e o conflito entre seus interesses concorrentes. Para Licht (2011), poder é um conceito central na governança corporativa, que representa um enquadramento que visa regular seu exercício. A disputa atual entre a orientação da maximização do valor do acionista e a visão da responsabilidade social mais ampla da empresa pode ser percebida como um exemplo dessa tensão.

Trazendo a discussão dessa tensão ou disputa de poder na governança para o âmbito das empresas estatais, deve ser considerado que essa situação produz significativas consequências. Se a primazia do lucro e a maximização do valor para o acionista permitem um objetivo claro e critérios inequívocos de avaliação da empresa privada, para a estatal a disputa entre distintos objetivos e interesses e as dificuldades em avaliar o desempenho, especialmente na EP, tornam a governança mais complexa. O poder é disputado entre vários grupos políticos, o que por vezes permeia a própria hierarquia organizacional com múltiplos interesses e orientações, refletidos nas várias diretorias. A ideia difusa da "função social da empresa", reiterada pelo art. 27 da Lei no 13.303, cria orientações passíveis de variadas interpretações. Se antes essa interpretação ocorria no âmbito do ministério supervisor, produzindo demandas pela atuação da estatal em políticas públicas muitas vezes distintas de sua missão, após a promulgação da nova Lei das Estatais, que fortaleceu a autonomia dos administradores, interpretar e perseguir a "função social" pode se tornar um arbítrio do conselho e executivos, aumentando seu poder discricionário.

Esse contexto de múltiplos objetivos, constrangimentos e influências externas de interesses de stakeholders expressivos é avaliado por Koppel (2005) como um ambiente capaz de produzir expectativas conflitantes sobre os objetivos e prioridades da organização e concepções discrepantes de responsabilidade e accountability, que minam a eficácia organizacional. Organizações que tentam atender a expectativas conflitantes provavelmente são disfuncionais, terminando por não agradar a ninguém enquanto tentam agradar a todos, promovendo a "doença" denominada por Koppel (2005) como uma multiple accountability disorder (MAD). As questões levantadas sobre o papel que a Petrobras deveria desempenhar na greve dos caminhoneiros de maio de 2018 , conflitando aspectos de natureza política, econômica e de estratégia nacional, exemplificam a dificuldade de compatibilizar expectativas de múltiplos stakeholders e atender às diversas dimensões de accountability relativas a esses públicos. 
Um equivalente nas empresas privadas seria a orientação para os stakeholders, cujos interesses deveriam guiar a atuação das empresas. Jensen (2010) critica essa abordagem, afirmando que "Sem a clareza da missão proporcionada por uma função- objetivo única, as empresas que adotam a teoria das partes interessadas (stakeholders) experimentarão confusão gerencial, conflito, ineficiência e talvez até fracasso competitivo"3. ( dessa questão, a exigir um adequado aprofundamento, o objetivo de apresentála aqui é apenas indicar a dificuldade, ou impossibilidade, de maximização de múltiplos objetivos. Como adiciona Jensen (2010), "Teoria dos stakeholders direciona os gestores a servirem a muitos mestres" ${ }^{4}$ (tradução nossa), o que pode ser complementado pela consideração de que uma profusão e concorrência de distintos objetivos decorrentes da proposta de atenção aos vários stakeholders pode servir para ampliar significativamente o poder discricionário do gestor (agente), retornando aos problemas centrais que a governança corporativa originalmente buscou tratar e amplificando o problema de agência.

Tratando do problema de agência no setor público, Przeworski (2003) considera que o desempenho dos sistemas econômicos depende de três relações: entre cidadãos e políticos eleitos; entre políticos e burocratas; e as relações entre o Estado e os agentes econômicos (regulação). Essas três relações representam, além dos problemas de agência entre as partes, a ocorrência de um nível de intermediação entre os interesses dos cidadãos e a máquina pública responsável por sua execução, nível esse representado pelo sistema político.

Se de um lado essa intermediação reduz o poder direto de influência da sociedade na empresa estatal, por outro traz uma amplificação do dever fiduciário do sistema político, que se torna o principal em uma relação de agência com a empresa, representando indiretamente os interesses da sociedade. Se a nova legislação trouxe o benefício de fortalecer a administração das empresas estatais, reduzindo influências indevidas nas escolhas estratégicas e atividades cotidianas, é necessário que não ocorram excessos na transferência dos poderes inerentes à propriedade aos administradores. O principal permanece sendo o sistema político, que deve traduzir as demandas da sociedade e interpretar o comando legal da "função social", sem transferir esse poder discricionário aos administradores, mas sem transformar a empresa em apêndice da administração direta e resguardando a autonomia dos administradores. Em uma relação de governança, o principal deve ser capaz de definir e aprovar as prioridades estratégicas, e a administração

\footnotetext{
3 "Without the clarity of mission provided by a single-valued objective function, companies embracing stakeholder theory will experience managerial confusion, conflict, inefficiency, and perhaps even competitive failure".

4 "stakeholder theory directs corporate managers to serve 'many masters'".
} 
de alcançá-las com a máxima eficiência, o que vale tanto para empresas privadas como para estatais.

\section{Situando a atuação da empresa estatal no Brasil}

Para prosseguir na análise dos avanços e obstáculos de desenvolvimento da governança da empresa estatal, é necessário, antes, uma breve contextualização, para, na seção seguinte, examinar como esse contexto modela a ação dessas empresas e seu relacionamento com os principais stakeholders.

Empresa estatal representa um conceito amplo e muitas vezes mal definido ou compreendido. Embora a Organisation for Economic Cooperation and Development (OECD) limite sua abrangência àquelas empresas nas quais o governo central exerce a propriedade e o controle (OECD, 2017), no Brasil são consideradas todas aquelas de posse ou controle do Estado, podendo ser a União, estados, Distrito Federal ou municípios. O Decreto-Lei no 200, de 1967, trouxe os conceitos de empresa pública (EP) e sociedade de economia mista (SEM) como entes da administração pública indireta (BRASIL, 1967). Mais recentemente, a Lei no 13.303, de 2016, que veio disciplinar o art. 173 da Constituição Federal, reforçou o conceito:

Art. $3^{\circ}$ Empresa pública é a entidade dotada de personalidade jurídica de direito privado, com criação autorizada por lei e com patrimônio próprio, cujo capital social é integralmente detido pela União, pelos Estados, pelo Distrito Federal ou pelos Municípios.

Art. $4^{\circ}$ Sociedade de economia mista é a entidade dotada de personalidade jurídica de direito privado, com criação autorizada por lei, sob a forma de sociedade anônima, cujas ações com direito a voto pertençam em sua maioria à União, aos Estados, ao Distrito Federal, aos Municípios ou a entidade da administração indireta (BRASIL, 2016).

A lei torna clara, então, a possibilidade de a sociedade de economia mista se financiar com capital privado diretamente via equity, ou seja, pela participação de investidores privados na sociedade.

Não existem dados consolidados sobre números das empresas estatais no país, sendo necessário recorrer a inúmeras bases, tarefa complexa ou mesmo inviável quando expandida para o exame da situação das estatais nos municípios. No plano federal, devem ser destacados os avanços recentes na capacidade de acompanhamento dessas empresas e divulgação de informações, especialmente a partir da criação da Comissão Interministerial de Governança Corporativa e de Administração de Participações Societárias da União (CGPAR), em 2007, pela incorporação da governança das estatais no próprio nome do departamento do 
Ministério do Planejamento, Orçamento e Gestão responsável pela supervisão dessas empresas, e principalmente pela atribuição a esse departamento do status de secretaria, como Secretaria de Coordenação e Governança das Empresas Estatais (Sest), em 2016, aumentando o poder de disciplinar o sistema.

Nos estados, ainda há grande heterogeneidade nos processos de acompanhamento e governança das estatais, sendo o nível de informação sobre esses processos ainda menor para os municípios. Apesar dos melhores esforços, não parece ser possível identificar o tamanho representado pelas empresas estatais no país.

Segundo levantamento do Observatório das Estatais da Fundação Getúlio Vargas, em apresentação em seminário em maio de 2017, o país tinha então um total de 446 empresas estatais, sendo 154 na União (34,53\%), 232 nos estados (52,02\%) e 60 nos municípios $(13,45 \%)$. A destacar a constatação do Observatório sobre esse conjunto de empresas de que "Sabemos muito pouco, nem sabemos quantas são!" (HOLLAND, 2017).

Entretanto, esse número pode ser bem maior conforme o critério de classificação adotado, o que permitiria incluir também inúmeras subsidiárias, controladas ou mesmo sociedades de propósito específico (SPEs). Conforme o Decreto no $3.735 / 2001$, que define diretrizes para as empresas estatais federais:

Art. $1 \S 1^{\circ}$ Para os fins do disposto neste Decreto, consideram-se empresas estatais federais as empresas públicas, sociedades de economia mista, suas subsidiárias e controladas e demais empresas em que a União, direta ou indiretamente, detenha a maioria do capital social com direito a voto (BRASIL, 2001).

Para o número de empregados, os dados da Relação Anual de Informações Sociais (RAIS), organizados pelo Ministério do Trabalho e Emprego, são mais fidedignos. Nas estatais federais, o pessoal efetivo empregado era de $533.188 \mathrm{em}$ 2016 e 504.444 em 2017, conforme o 5o Boletim das Empresas Estatais Federais, produzido pela Secretaria de Coordenação e Governança das Empresas Estatais, do Ministério do Planejamento (BRASIL, 2017). 
Quadro 1 - número de empregados das empresas estatais, com vínculo ativo em 31 de dezembro de 2016

\begin{tabular}{|l|l|l|l|}
\hline UF & Sociedade Mista & Empresa pública & TOTAL \\
\hline Acre & 1.029 & 2.648 & 3.677 \\
\hline Alagoas & 5.968 & 2.867 & 8.835 \\
\hline Amapá & 1.087 & 728 & 1.815 \\
\hline Amazonas & 4.649 & 3.712 & 8.361 \\
\hline Bahia & 23.131 & 13.623 & 36.754 \\
\hline Ceará & 9.595 & 9.740 & 19.335 \\
\hline Distrito Federal & 22.828 & 57.229 & 80.057 \\
\hline Espírito Santo & 8.932 & 5.518 & 14.450 \\
\hline Goiás & 21.184 & 8.324 & 29.508 \\
\hline Maranhão & 6.921 & 5.463 & 12.384 \\
\hline Mato Grosso & 2.286 & 4.591 & 6.877 \\
\hline Mato Grosso do Sul & 2.870 & 4.011 & 6.881 \\
\hline Minas Gerais & 29.411 & 51.386 & 80.797 \\
\hline Pará & 8.509 & 7.351 & 15.860 \\
\hline Paraíba & 5.546 & 5.185 & 10.731 \\
\hline Paraná & 23.071 & 17.494 & 40.565 \\
\hline Pernambuco & 15.489 & 13.395 & 28.884 \\
\hline Piauí & 5.001 & 3.408 & 8.409 \\
\hline Rio de Janeiro & 76.421 & 39.008 & 115.429 \\
\hline Rio Grande do Norte & 9.254 & 3.124 & 12.378 \\
\hline Rio Grande do Sul & 40.797 & 25.351 & 66.148 \\
\hline Rondônia & 1.918 & 3.778 & 5.696 \\
\hline Roraima & 2.162 & 740 & 2.902 \\
\hline Santa Catarina & 15.787 & 13.079 & 28.866 \\
\hline São Paulo & 103.150 & 76.224 & 179.374 \\
\hline Sergipe & 7.584 & 2.647 & 10.231 \\
\hline Tocantins & 1.232 & 1.494 & 837.926 \\
\hline Total & 455.812 & 382.118 & \\
\hline Sal & & & \\
\hline
\end{tabular}

Fonte: RAIS.

Um total de 26 empresas estatais, de controle dos vários níveis da federação, estavam listadas na B3 (antiga BM\&FBovespa) no final de 2016. Essas 26 empresas totalizavam 284.977 empregados, sendo que apenas o Banco do Brasil, com 100.622 empregados, a Eletrobras, com 24.539, e a Petrobrás, com 68.829, representavam juntas $68 \%$ da amostra. Conforme informações coletadas no sistema Economática, o valor de mercado dessas três empresas alcançou $\mathrm{R} \$ 319.272$ milhões, com a Petrobrás representando $65 \%$ desse total. 
Segundo divulgado no Formulário de Referência das empresas, a mediana da remuneração anual total do presidente executivo nessas empresas estatais listadas foi de $\mathrm{R} \$$ 648.305,00, considerando parcelas fixas, variáveis e outros benefícios, sendo a remuneração total máxima desse dirigente de $\mathrm{R} \$ 2.240 .007,40$, na Petrobras, e mínima de $\mathrm{R} \$ 372.776,81$, na EMAE, de São Paulo, retiradas três empresas com total menor que $\mathrm{R} \$ 200$ mil anuais. Para o setor privado, as três maiores remunerações de presidentes de empresas listadas nesse ano foram de $\mathrm{R} \$$ 27.170.268, na BR Malls Participações; de R\$ 22.015.207,18, na Hypermarcas; e de R\$ 21.353.406,20, na Qualicorp.

Esses dados são obtidos no Formulário de Referência (FR), relatório de divulgação obrigatória pelas empresas listadas. Em seu item 13.2, o FR traz os números referentes ao total da remuneração dos órgãos, e no 13.11, os valores mínimos e máximos. Entretanto, 49 empresas se utilizam de liminar para não divulgarem essas informações aos acionistas e mercados. Importante destacar, nesse contexto, que nenhuma empresa estatal fez uso de liminar, um indicativo de valorização da transparência e prestação de contas.

A título de comparação, estudo do Instituto Brasileiro de Governança Corporativa (IBGC, 2017), com base no conjunto das empresas listadas nesse ano de 2016, identificou uma remuneração média para o total dos membros da diretoria, conforme item 13.2 do FR das empresas - equivalente à remuneração total da diretoria dividido pelo número de membros - de $\mathrm{R} \$ 2.213 .773$ e mediana de $\mathrm{R} \$$ 1.404.307. O Quadro 2 a seguir mostra como a remuneração dos administradores das empresas estatais é, consistentemente, inferior àquela praticada no mercado privado, representando na média aproximadamente um terço.

Quadro 2 - Remuneração dos membros da diretoria das empresas listadas, 2016

\begin{tabular}{|c|c|c|c|c|}
\hline \multirow[b]{2}{*}{ Tipo de controle } & \multicolumn{3}{|c|}{$\begin{array}{c}\text { Médias de remuneração divulgadas pelas } \\
\text { empresas (R\$) }\end{array}$} & \multirow[b]{2}{*}{$\begin{array}{l}\text { No. de } \\
\text { Empresas }\end{array}$} \\
\hline & Média & Mediana & Máximo & \\
\hline Estatal & 796.385 & 674.305 & 2.212 .752 & 26 \\
\hline Estrangeiro & 2.598 .118 & 2.260 .399 & 5.140 .201 & 8 \\
\hline Privado & 2.365 .923 & 1.596 .154 & 19.562 .751 & 222 \\
\hline Amostra total & 2.213 .773 & 1.404 .307 & 19.562 .751 & 256 \\
\hline
\end{tabular}

Fonte: IBGC (2017). 


\section{Mapeando os stakeholders da empresa estatal}

\section{O papel do Estado como stakeholder preponderante}

A consideração do problema de agência como central à governança corporativa representa o predomínio da lógica do acionista como ator preponderante no comando da empresa, em nome de cujos interesses a empresa deve ser gerida. Uma longa história explica a primazia do acionista, justificada - ou racionalizada - posteriormente pela localização do acionista como último elo na cadeia de apropriação dos resultados da empresa, de modo que este apenas teria ganhos se todos os demais fossem remunerados, e pela impossibilidade de maximização de mais de um objetivo empresarial (residual claims), embrião da corrente da maximização do valor do acionista (JENSEN, 2010; FRIEDMAN, 1970; STOUT, 2012).

Como discutido, o fortalecimento das boas práticas de governança corporativa foi impulsionado pela necessidade dos acionistas em garantirem seu comando nos destinos das empresas, fragilizado desde a pulverização da propriedade e do empoderamento dos executivos, como discutido por Berle e Means, em texto original de 1932, onde caracterizaram a separação propriedade-controle presente na empresa americana do início do século 20 (BERLE; MEANS, 1987). Entretanto, no Brasil e na maioria dos países onde predomina o modelo de propriedade concentrada, o problema maior remete à relação entre controladores e minoritários, sendo que o reduzido poder de influência e controle dos acionistas com menores participações abre espaço para expropriações, conforme analisado anteriormente.

Essa situação não é diferente em empresas privadas com controle definido e nas SEM. Assim como o controlador privado pode realizar ações de self-dealing, também o ente público controlador da SEM pode guiá-la para fins distintos daqueles implícitos em seu estatuto, inclusive de barganha política, aproveitando sua posição de controle na empresa para obter benefícios particulares - individuais ou do grupo político - pela expropriação de acionistas minoritários. Certamente que essa expropriação quando realizada por ente estatal é muito mais perversa, pois, além de prejudicar os minoritários de uma SEM em particular, traz uma sinalização negativa a todos os potenciais investidores sobre a governança de todo o conjunto das SEM, aumentando o risco e, consequentemente, o custo de obtenção de capital por essas empresas.

Independentemente de considerações sobre benefícios ou desvantagens, essa primazia do acionista - mesmo que esse acionista seja o Estado - é menos efetiva para orientar a atuação da empresa estatal do que para as empresas privadas. Diversas razões, algumas óbvias outras nem tanto, mostram as falhas de se basear 
nessa primazia para a estatal, o que pode remeter ao problema da existência de múltiplos objetivos, por vezes conflitantes.

Como observam Ring e Perry (1985), gestores governamentais - conceituação que, nesse aspecto, pode ser estendida aos gestores das estatais - devem prestar atenção a um público muito mais diverso que no setor privado, lidando com expectativas e influências de conjunto mais amplo de stakeholders, que avaliam os resultados de maneiras distintas e, em geral, difíceis de conciliar. Esse é o desafio de responder às expectativas dos stakeholders, que indiretamente, no modelo de Przeworski (2003), representam o avaliador final da ação estatal.

Em sua origem e motivação de criação, a empresa estatal deve atender a uma função social. Como disposto no Capítulo III da Lei no 13.303 , que trata da função social da empresa pública e da sociedade de economia mista:

Art. 27. A empresa pública e a sociedade de economia mista terão a função social de realização do interesse coletivo ou de atendimento a imperativo da segurança nacional expressa no instrumento de autorização legal para a sua criação.

Sujeitas, via de regra, tanto ao arcabouço jurídico das empresas privadas como a muitos dos normativos da administração pública direta, as empresas estatais devem atender a requisitos mais amplos de transparência, de prestação de contas, de fiscalização e análise por auditorias externas, de limites à internacionalização e diversificação, de restrições na seleção de fornecedores (principalmente se internacionais), entre vários outros. Em sua atuação, a estatal tem baixa autonomia em suas políticas de contratação, demissão e remuneração de pessoal, nos orçamentos de investimento, e na adoção de estratégias que tragam impactos ou externalidades sobre a sociedade, como o fechamento de instalações industriais não econômicas, reorganização geográfica da rede de agências ou filiais.

Diferentemente das empresas privadas, as empresas estatais não podem solicitar falência, como disposto no art. 2o da Lei no 11.101/2005 (BRASIL, 2005). Também estão sujeitas a eventuais excessos nos pagamentos de dividendos aos governos e à frequente dependência sobre aportes e transferências de recursos pelo governo. Empresas públicas dependentes, aquelas que precisam do aporte de recursos financeiros do ente controlador para pagamento de despesas com pessoal ou custeio em geral, têm agravado esse problema de perda de autonomia.

Empresas estatais não podem abrir subsidiárias, sendo exigida autorização legislativa (Constituição Federal, art. 37 inciso XX) para cada nova empresa ou autorização ampla. Neste caso autorizativo, são exemplos a Lei no 9.478/1997, ou Lei do Petróleo (BRASIL, 1997), que em seu artigo 64 autoriza a Petrobras a constituir 
subsidiárias; a Lei no 12.490/2011, que no art. 11, confere essa autorização aos Correios (BRASIL, 2011); e a Lei no 11.908/2009, art. 1으, que autoriza o Banco do Brasil e a Caixa Econômica Federal "a constituir subsidiárias integrais ou controladas, com vistas no cumprimento de atividades de seu objeto social" (BRASIL, 2009). De qualquer forma, permanece válido o argumento de que o crescimento das empresas estatais via abertura de subsidiárias ou crescimento inorgânico por aquisições é bastante dificultado (conforme a Lei $\mathrm{n}$ o $13.303 / 16$, art $2^{\circ}, \S 2^{\circ}$ ).

Apesar da maior independência da administração introduzida pela Lei no 13.303/16, empresas estatais estão sujeitas, em essência, ao ciclo político, uma vez que a situação de insulamento não seria tampouco desejável. Estão também sujeitas aos arranjos e interesses das coalizões (temporárias) de poder, e mais expostas às pressões de grupos políticos e interesses diversos, como de fornecedores, empregados e sindicatos, grupos sociais etc. Por certo é também muito mais intensa a pressão sobre as estatais pela melhor adequação às práticas de responsabilidade socioambiental, principalmente aquelas de maior porte, das quais frequentemente se espera que tenham um papel de liderança na adoção das melhores práticas difundidas no mercado.

\section{Expectativas e influência dos demais stakeholders da empresa estatal}

Apesar da propriedade ou controle estatal, o Estado não é o único ator influente no mapa dos stakeholders dessas empresas. Enquanto na SEM o acionista privado ocupa um papel fundamental ao trazer recursos financeiros para apoiar o desenvolvimento dos projetos da empresa e na ampliação dos agentes e mecanismos de controle externo, para as EP permanece relevante a influência de atores com interesses menos relacionados ao desempenho da empresa, podendo exercer pressões divergentes da orientação de sua função social ou atuar na captura política da empresa.

Desenvolvendo a análise iniciada na seção anterior, é possível inferir que, diferentemente da empresa privada listada, com ações negociadas na bolsa, as estatais, e principalmente empresas públicas, têm sérias barreiras, ou mesmo impossibilidade, para seguir uma orientação de maximização do valor ao acionista ou de sua lucratividade. É mister destacar que essa consideração não representa uma justificativa para ações de ineficiência gerencial, uso da estatal para execução de ações públicas distintas de funções fundamentais ou impropriedade no uso dos recursos públicos. Particularmente no caso da SEM, aceitar a participação dos sócios privados na propriedade ratifica seu compromisso em buscar os melhores resultados econômicos, sob pena de prejudicar a confiança futura em seus projetos - com consequente dificuldade de captação de funding privado. 
Não é válido o argumento de que o investidor da SEM sabe os riscos que corre e assume a possibilidade de menores retornos, pois nunca é precificado todo o potencial de intervenção do governo na empresa em prejuízo do lucro e do retorno aos acionistas, inclusive ao próprio Estado. Quanto maior a interferência dos governos na administração da estatal, menos atrativa ela se torna ao investidor privado e mais dificuldades terá de captar recursos no mercado. Em consequência, serão maiores seus custos de capital, com prejuízos à eficiência e competitividade, o que significa que a sociedade terá que suportar esses custos adicionais e desviar recursos de outras políticas públicas para financiar a estatal. Ou seja, uma estatal ineficiente traz custos para toda a sociedade, razão pela qual se torna fundamental promover a boa governança e gestão dessas empresas, bem como um acompanhamento próximo de seu desempenho.

Decorre ainda que, enquanto para as empresas privadas listadas, o acionista (shareholder) ocupa uma posição central no mapa dos stakeholders, tanto na SEM como na EP, o conjunto de interesses com potencial para deslocar a ação e a estratégia dessas empresas é muito mais amplo, reforçando a premissa da multiple accountability (KOPPEL, 2005). Conforme Yeung (2005), a governança da empresa estatal está sujeita a influências do Estado, mercado e sociedade civil, que são influências de natureza muito distintas em termos de fontes de poder, valores, racionalidades e normas, o que pode gerar conflitos nas orientações. Assim, mesmo no caso de SEM, onde há um acionista controlador, a multiplicidade e variedade de interesses e stakeholders influentes no interior do sistema político cria ambiguidades na definição dos objetivos, na execução das estratégias, e na avaliação dos resultados e efetividade da atuação dessas empresas.

Para as empresas privadas listadas em bolsa, o grupo controlador acumula a maioria, senão a plenitude, do poder para definir as estratégias e objetivos da empresa, e o problema clássico da separação propriedade-controle se mostra menos significativo. A orientação de maximização do valor para o acionista facilita o processo decisório dos sócios, a priorização das ações e a avaliação da administração. É mínima a influência dos acionistas minoritários, expressa em geral apenas por estratégias de exit, e o mercado de capitais tem pouco poder direto na empresa ou frente a seus controladores, embora esse poder seja fortemente ampliado em momentos da necessidade de aportes de capital para investimento. Ainda assim, a disseminação de indicadores de desempenho e benchmarks padronizados facilita a comparação entre as empresas listadas, pressionando as administrações e influenciando o reconhecimento, pelo mercado de trabalho e pelos headhunters, da capacidade e competência dos executivos. Estratégias de legitimidade, como participação em segmentos especiais de listagem da B3 e 
adesão a códigos, relatos e práticas de responsabilidade socioempresarial operam para melhorar a aceitação da empresa pela sociedade. A fiscalização interna pode ser dependente dos interesses dos controladores, e a externa, realizada por agentes públicos, tem muitas vezes natureza formalística e ex-post.

Parte dessa síntese se aplica também às SEM, mas as diferenças são significativas. Ao contrário do grupo controlador da empresa privada, o ente governamental não tem na maximização do resultado seu objetivo central, abrindo espaço para disputas entre os distintos grupos políticos e coalizões de poder, frequentemente temporárias, para ditar seus objetivos e ações. É menor a preocupação com minoritários e investidores, dada a capacidade do governo de capitalizar a empresa, mesmo que ao custo de retirar recursos de outras políticas públicas.

O tempo é também uma dimensão de profunda diferenciação para empresas privadas e estatais. Enquanto para a empresa privada o tempo é vinculado aos ciclos dos negócios e os prazos dos planos definidos pelas estratégias, a empresa estatal está sujeita às pressões do tempo político (RING; PERRY, 1985), quando as restrições de tempo tendem a ser influenciadas pelas legislaturas e mandatos políticos, ou pela duração do emprego das autoridades públicas. O impacto político da ação da empresa, percebida e desejada por um público muito mais amplo que os minoritários, é mais importante para o principal (Estado-governo) que seus resultados econômicos. E, via de regra, a continuidade e sustentabilidade das ações e os resultados de longo prazo são menos importantes que amplas e midiáticas estratégias. Como já afirmava Smith há quase meio século e permanece atual: "O fato é que as nações do Terceiro Mundo não foram capazes de se dar ao luxo de implementar políticas incrementais. As políticas tendem a ser ambiciosas, varrendo programas abrangentes destinados a promover o desenvolvimento e a reforma social." (SMITH, 1973, p. 199, tradução nossa55)

Nas elaborações da teoria da agência e mecanismos de controle da governança, uma estrutura adequada de remuneração dos executivos, em montantes e adequação da parcela variável, é essencial para alinhamento de interesses motivando os gestores a agirem com o objetivo principal (BEBCHUK; FRIED, 2003), enquanto a existência de um mercado de trabalho de executivos opera de forma eficaz para induzir um comportamento alinhado desses administradores (AGRAWAL; KNOEBER, 1996). Entretanto, além de um mercado de trabalho de executivos especializados em SEM frágil e pouco estruturado, as baixas remunerações relativamente aos equivalentes privados inibem o interesse de potenciais candidatos. Soma-se a esse quadro que a autonomia de ação dos administradores das estatais é sensivelmente

\footnotetext{
5 "The fact is that the Third World nations have not been able to afford the luxury of incremental policymaking. Policies tend to be ambitious, sweeping programs designed to bring about development and social reform."
} 
reduzida, sujeita à a provação externa de seus investimentos, de decisões de políticas de pessoal, fusões e aquisições e várias outras ações. Possivelmente a maior diferença das SEM para empresas privadas listadas é a intensidade do controle realizado pelas instituições governamentais, a exemplo do Tribunal de Contas da União. A destacar também o poder dos empregados nas estatais, influenciando nas ações e na fiscalização, e, no caso das estatais federais, participando do conselho de administração, conforme a Lei no 12.353/10 (BRASIL, 2010).

Assim, para os executivos das estatais configura-se um quadro de baixa autonomia, elevados riscos e remuneração significativamente inferior à praticada no mercado privado. Vale acrescentar que executivos e conselheiros da estatal devem ainda atentar para os dispositivos da Lei no 8.429/1992 (Lei de Improbidade Administrativa) (BRASIL, 1992a), do Código de Conduta da Alta Administração Federal, da Lei no 8.443/1992 (Lei Orgânica do Tribunal de Contas da União) (BRASIL, 1992b), e ainda da Lei no 12.846/2013 (Lei Anticorrupção) (BRASIL, 2013). Não é, por certo, um cenário estimulante para a atração de executivos.

Para as empresas públicas, contudo, a análise é ainda mais distinta. Por atuarem tipicamente em contextos de monopólio de mercado, em geral pela falta de interesse de empresas privadas, é mais difícil construir indicadores para comparação, o que, somado à ausência de investidores privados na propriedade, torna rara ou inexistente a supervisão e controle por atores de mercado, exceto para as grandes empresas públicas que atuam também mais diretamente no mercado privado, como o BNDES e a Caixa. Por sua vez, a presença de um único acionista ou proprietário pode inibir a transparência e a prestação de contas, tanto pela especialização quanto pelo menor número de interessados. Um dos maiores riscos para as empresas públicas, principalmente as dependentes, é serem consideradas ou tratadas pelo ministério supervisor como órgãos da administração direta, impactando em limitações a suas decisões e à exposição à linha hierárquica de comando do ministério. Para a administração direta, a empresa estatal ainda se apresenta, frequentemente, como um espaço de maior amplitude de ação e autonomia financeira, menos sujeita ao monitoramento direto da sociedade ou dos órgãos de controle, dadas as especificidades de sua atuação, condições que podem estimular sua captura pelo sistema político para ações diversas de suas funções.

Tanto para as SEM como para as empresas públicas, o problema maior parece não residir, contudo, na relação de agência e na supervisão da administração, mas na própria atuação do Estado como principal. Ao ter dificuldades de alinhar grupos políticos e trazer orientações negociais claras à estatal, tentar influenciar sua atuação para a execução de políticas públicas não relacionadas à sua missão (problema minimizado pela carta anual com os compromissos de consecução 
de objetivos de políticas públicas, exigida no art. 8o da Lei no 13.303/16), exigir condições desequilibradas nas negociações com a empresa, negociar metas pouco realistas ou exigir pagamento de dividendos que inviabilizem projetos necessários de investimento da empresa, o ente estatal traz para si a responsabilidade pelo problema de agência. A dificuldade não é o agente e seu potencial de oportunismo, mas o principal e suas falhas de coordenação, sugerindo o maior poder das novas abordagens para a análise das questões de governança dessas empresas.

O Quadro 3, elaborado com base nos argumentos apresentados, analisa o papel dos principais stakeholders e influências nos três tipos de empresa, tendo por base que, no Brasil, a grande maioria das empresas privadas listadas tem um acionista ou grupo que controla a propriedade, detendo individualmente ou por acordo de acionistas mais de metade das ações votantes. Importante destacar que a análise apresentada no Quadro 3 visa realizar uma síntese da discussão anterior e de identificação do poder dos stakeholders envolvidos. Certamente há inúmeras nuances entre empresas nos vários grupos, a exemplo dos mercados regulados, que tornam necessários posteriores aprofundamentos e detalhamentos no Quadro, bem como sua validação empírica.

Quadro 3 - Principais stakeholders e mapa de influências

\begin{tabular}{|c|c|c|c|}
\hline & $\begin{array}{l}\text { Empresa privada } \\
\text { listada (com } \\
\text { controlador) }\end{array}$ & $\begin{array}{l}\text { Sociedade de } \\
\text { economia mista }\end{array}$ & Empresa pública \\
\hline $\begin{array}{l}\text { Principais } \\
\text { mecanismos de } \\
\text { controle interno }\end{array}$ & $\begin{array}{l}\text { Conselho de } \\
\text { administração e } \\
\text { auditoria }\end{array}$ & $\begin{array}{l}\text { Conselho de } \\
\text { administração, } \\
\text { conselho fiscal e } \\
\text { auditoria }\end{array}$ & $\begin{array}{l}\text { Conselho de } \\
\text { administração, } \\
\text { conselho fiscal e } \\
\text { auditoria }\end{array}$ \\
\hline $\begin{array}{l}\text { Principais } \\
\text { mecanismos de } \\
\text { controle externo }\end{array}$ & $\begin{array}{l}\text { Pressão de } \\
\text { investidores } \\
\text { e mercado de } \\
\text { capitais } \\
\text { Mercado de } \\
\text { trabalho de } \\
\text { executivos }\end{array}$ & $\begin{array}{l}\text { Órgãos estatais } \\
\text { de fiscalização } \\
\text { e controle, em } \\
\text { especial tribunais } \\
\text { de contas. Pressão } \\
\text { de investidores } \\
\text { e mercado de } \\
\text { capitais }\end{array}$ & $\begin{array}{l}\text { Órgãos estatais } \\
\text { de fiscalização } \\
\text { e controle, em } \\
\text { especial tribunais } \\
\text { de contas }\end{array}$ \\
\hline $\begin{array}{l}\text { Principais } \\
\text { influências na } \\
\text { estratégia }\end{array}$ & $\begin{array}{l}\text { Administradores } \\
\text { e demandas de } \\
\text { investidores }\end{array}$ & $\begin{array}{l}\text { Demandas de } \\
\text { investidores } \\
\text { Demandas } \\
\text { de governo } \\
\text { (na União, } \\
\text { do ministério } \\
\text { supervisor) }\end{array}$ & $\begin{array}{l}\text { Demandas } \\
\text { de governo } \\
\text { (na União, } \\
\text { do ministério } \\
\text { supervisor) }\end{array}$ \\
\hline
\end{tabular}




\begin{tabular}{|c|c|c|c|}
\hline Objetivo principal & $\begin{array}{l}\text { Maximização } \\
\text { do valor para o } \\
\text { acionista }\end{array}$ & $\begin{array}{l}\text { Maximização } \\
\text { do Valor para } \\
\text { o acionista } \\
\text { Atendimento da } \\
\text { função social }\end{array}$ & $\begin{array}{l}\text { Atendimento da } \\
\text { função social }\end{array}$ \\
\hline $\begin{array}{l}\text { Medida de } \\
\text { resultado }\end{array}$ & $\begin{array}{l}\text { Lucro } \\
\text { Valor da ação }\end{array}$ & $\begin{array}{l}\text { Lucro } \\
\text { Valor da ação } \\
\text { Objetivos de } \\
\text { governo }\end{array}$ & $\begin{array}{l}\text { Objetivos de } \\
\text { governo }\end{array}$ \\
\hline $\begin{array}{l}\text { Medida de } \\
\text { eficiência }\end{array}$ & $\begin{array}{l}\text { Benchmarks e } \\
\text { comparações com } \\
\text { concorrentes }\end{array}$ & $\begin{array}{l}\text { Benchmarks e } \\
\text { comparações com } \\
\text { concorrentes }\end{array}$ & $\begin{array}{l}\text { Referenciais } \\
\text { internos definidos } \\
\text { pela empresa }\end{array}$ \\
\hline $\begin{array}{l}\text { Autonomia dos } \\
\text { administradores }\end{array}$ & Muito alta & Média & Baixa \\
\hline $\begin{array}{l}\text { Potencial para } \\
\text { oportunismo } \\
\text { gerencial } \\
\text { (problema de } \\
\text { agência) }\end{array}$ & Alto & Médio & Baixo \\
\hline $\begin{array}{l}\text { Influência da } \\
\text { sociedade nas } \\
\text { atividades }\end{array}$ & Baixa & Muito alta & Muito alta \\
\hline $\begin{array}{l}\text { Influência de } \\
\text { fornecedores nas } \\
\text { decisões }\end{array}$ & Baixa & Alta & Alta \\
\hline $\begin{array}{l}\text { Influência do } \\
\text { sistema político } \\
\text { nas estratégias e } \\
\text { ações }\end{array}$ & Baixa & Muito alta & Muito alta \\
\hline $\begin{array}{l}\text { Influência dos } \\
\text { empregados }\end{array}$ & Baixa & Alta & Alta \\
\hline
\end{tabular}

Fonte: elaboração própria.

É importante destacar que esse Quadro, elaborado de forma empírica a partir das análises desenvolvidas, visa apontar distinções de orientação na organização e atuação das empresas estatais, destacando pontos principais de diferenciação, e facilitando a exploração dos desafios futuros, tratada na seção seguinte. Certamente os aspectos levantados não são isentos de controvérsias ou avaliações distintas em casos específicos, questões que poderiam eventualmente ser tratadas em futuros estudos. 


\section{Consolidando desafios e propostas de caminhos futuros}

Traçado anteriormente o cenário de atuação das estatais, esta seção visa alinhar essas discussões à proposta deste número especial da Revista do Serviço Público, qual seja, "Repensando o Estado Brasileiro" e a discussão sobre os desafios da governança das empresas estatais nesse movimento, tendo como referência o novo contexto que se apresenta após a aprovação da nova Lei das Estatais.

Mesmo após a onda liberal dos anos 1980 e 1990, as empresas estatais permanecem com uma significativa presença e influente força global. Como destaca estudo da PwC, a proporção das empresas estatais no grupo das empresas da Fortune Global 500 passou de 9\%, em 2005, para 23\%, em 2014, influenciada certamente pela expansão das estatais chinesas (PwC, 2015).

No Brasil, a participação do Estado na economia via empresa estatal encontra apoio na sociedade. Pesquisa Datafolha em final de 2017 (DATAFOLHA, 2017) apontou que $70 \%$ dos brasileiros são contrários às privatizações das empresas estatais, e apenas $20 \%$ são favoráveis, números semelhantes quando o tema é privatização da Petrobrás. Além disso, para $67 \%$ da população (com base na amostra), as privatizações trazem mais prejuízos do que benefícios para o país. Entretanto, como aponta estudo da Instituição Fiscal Independente (IFI), do Senado, apresentado em janeiro de 2018 e abrangendo as 149 empresas estatais federais, 18 estavam classificadas como financeiramente dependentes da União e 131 independentes, sendo que nos dois anos anteriores a União havia direcionado mais de $\mathrm{R} \$ \mathbf{4 0}$ bilhões para manter essas empresas.

Assim, independente da visão sobre privatizar ou não, o tamanho e participação na economia do conjunto das empresas estatais no Brasil torna fundamental que se mantenham financeiramente saudáveis e capazes de articular os diversos interesses alinhados a sua função social, razões que reforçam a necessidade de adesão a boas práticas de governança.

O novo estatuto jurídico da empresa estatal trazido pela Lei no 13.303/16 e decretos posteriores, a exemplo do Decreto no 8.945/16 para as estatais federais, trouxe, no que tange à governança corporativa, mudanças significativas nas estruturas e condições de operação dessas empresas. Nesse contexto devem ser destacadas as exigências de aderência às melhores práticas de governança corporativa, especialmente nos aspectos de transparência, práticas de gestão de riscos e de controle interno, composição da administração e, no caso das SEM, dos mecanismos para proteção dos acionistas minoritários. O novo marco traz inúmeros comandos de boa governança, como o instrumento da carta anual, com explicitação dos objetivos de políticas públicas e política de distribuição de 
dividendos, a elaboração e sustentação via canal de denúncias do Código de Conduta e Integridade, regras para gestão de riscos e controles internos, e orientações sobre a função social da empresa estatal.

Mas possivelmente a principal inovação da lei, no que tange à governança das estatais (Título I), é quanto ao processo de escolha e avaliação dos administradores. Anteriormente o governo tinha plenos poderes para nomear os administradores - contemplando conselheiros de administração e executivos -, o que trazia os conflitos e coalizões políticas externos para dentro da gestão, reduzindo a eficiência e dispersando o foco dos administradores. Ao criar critérios para seleção técnica de administradores, requisitos de avaliação de desempenho e necessidade de participar de treinamento anual, essa legislação não apenas inova, como torna o quadro normativo de governança das estatais mais rigoroso e avançado que o das empresas privadas, onde avaliações de administradores, certos requisitos de transparência, enquadramento da atuação do acionista controlador, e independência do conselho são ainda critérios voluntários na maioria dos mercados. Como exemplo, enquanto as novas regras de listagem no Novo Mercado da B3, o nível mais elevado de práticas de governança das empresas, exigem que $20 \%$ dos conselheiros sejam independentes, a Lei $n$ o $13.303 / 16$ exige $25 \%$ de independentes.

Enfim, a análise mostra que, apesar de críticas pontuais a exemplo da vedação a quem participou nos últimos 36 (trinta e seis) meses de estrutura decisória de partido político ou campanha eleitoral (art. 17), a nova Lei das Estatais traz significativos avanços e promessas no que tange à governança corporativa dessas empresas. A adequação dos estatutos das empresas amplia a segurança dos acionistas minoritários, no caso das SEM, mas principalmente da sociedade, com a possibilidade de que a empresa estatal seja menos um instrumento de barganhas políticas e mais um instrumento de desenvolvimento, como definido pelas leis de criação específicas.

Em artigo anterior, de 2008, que refletia as orientações emanadas pela OECD em 2005, foi afirmado que:

As diretrizes propostas pela OCDE para as estatais têm como tônica fortalecer a autonomia da empresa e dos conselhos. Ambos os aspectos podem trazer profundos impactos sobre o monitoramento e controle das empresas, dando visibilidade a custos usualmente não discriminados, relativos à execução de políticas públicas, permitindo separar a eficiência empresarial da estatal da ação governamental, cujo custo deveria ser mais claramente disposto no orçamento público. Só assim será possível promover a qualidade da gestão, a meritocracia e o direcionamento das responsabilidades pelo alcance dos objetivos (FONTES FILHO; PICOLIN, 2008, p.1185). 
Por certo a nova legislação apresenta significativa aderência às recomendações da OECD (2005), atualizadas em 2015, e que vêm se disseminando pelos principais países.

No Brasil diversas instituições vêm divulgando recomendações para promoção da governança das empresas estatais, embora as principais recomendações sejam limitadas às SEM listadas na bolsa, como no caso do Instituto Brasileiro de Governança Corporativa (IBGC, 2017) e da B3, a bolsa de valores, com o Programa Destaque em Governança de Estatais. Iniciativa mais abrangente para as estatais federais é o Indicador de Governança desenvolvido pela Secretaria de Coordenação e Governança das Empresas Estatais (Sest), que operacionaliza exigências do novo marco regulatório e avalia a conformidade da governança das estatais, abrangendo tanto as SEM como as empresas públicas, inclusive empresas dependentes.

Nesse contexto, o novo marco regulatório contribui para alinhar as práticas e estruturas de governança corporativa das empresas estatais brasileiras às melhores práticas internacionais. São fortalecidos tanto os mecanismos internos de governança - tais como os sistemas de controle, autonomia e acompanhamento de desempenho dos administradores - como os mecanismos externos, principalmente externos ao setor público, que, embora ainda incipientes, deverão se desenvolver para supervisionar a atuação das estatais a partir da maior disponibilidade de informações e critérios de avaliação e comparação.

No entanto, como discutido no texto, ainda há lacunas que precisam ser direcionadas, principalmente na seleção e remuneração de administradores, e na atenção aos excessos dos controles externos que, muitas vezes divergentes, conflitantes ou sobrepostos, podem sufocar a ação dos administradores e inibir as decisões internas nas estatais. Como em qualquer empresa, o risco é parte dos negócios, e a construção nas organizações estatais de um clima de desconfiança e receio na tomada de decisões, com excesso de controles e receios de assumir responsabilidades, pode eventualmente contribuir para que as soluções sejam mais prejudiciais que os problemas que visavam resolver.

Concluindo esta análise, retornando ao problema principal-principal, deve ser reforçado que o novo marco regulatório traz significativos avanços na governança. É, contudo, ainda necessário que o principal - aqui considerado o Estado em sua plenitude, o que inclui os órgãos de controle - também seja capaz de se organizar para um adequado exercício de proprietário na empresa estatal, centralizando e coordenando as diversas demandas políticas e sociais, e assegurando, sem interferência, uma gestão financeiramente equilibrada e efetiva para o cumprimento da missão e função social da empresa. 


\section{Referências bibliográficas}

ABRANCHES, S. Presidencialismo de coalizão: o dilema institucional brasileiro. Dados, v. 31, n. 1, p. 5-38, 1988.

Agrawal, A.; KNOEBer, C. R. Firm performance and mechanisms to control agency problems between managers and shareholders. Journal of Financial and Quantitative Analysis, v. 31, n. 3, p. 377-397, 1996.

BEBCHUK, L. A.; FrIED, J. M. Executive compensation as an agency problem. Journal of Economic Perspectives, v. 17, n. 3, p. 71-92, Summer 2003.

BERLE, A. A.; MeANS, G. C. A moderna sociedade anônima e a propriedade privada. 2. ed. São Paulo: Nova Cultural, 1987.

BRASIL. Decreto-Lei no 200, de 25 de fevereiro de 1967. Dispõe sobre a organização da Administração Federal, estabelece diretrizes para a Reforma Administrativa e dá outras providências. Disponível em: <http://www2.camara.leg.br/legin/fed/ declei/1960-1969/decreto-lei-200-25-fevereiro-1967-376033-norma-pe.html>. Acesso em: 20 mar. 2018.

Constituição Federal, de 5 de outubro de 1988. Constituição da República Federativa do Brasil. Disponível em: <http://www2.camara.leg.br/legin/fed/ consti/1988/ constituicao-1988-5-outubro-1988-322142-norma-pl.html>. Acesso em: 20 mar. 2018.

. Lei no 8.429, de 2 de junho de 1992 (Lei de Improbidade Administrativa). Dispõe sobre as sanções a plicáveis aos agentes públicos nos casos de enriquecimento ilícito no exercício de mandato, cargo, emprego ou função na administração pública direta, indireta ou fundacional e dá outras providências. Disponível em: <http:// www2.camara.leg.br/legin/fed/lei/1992/lei-8429-2-junho-1992-357452-norma-pl. html>. Acesso em: 20 mar. 2018.

. Lei no 8.443, de 16 de julho de 1992 (Lei Orgânica do Tribunal de Contas da União). Dispõe sobre a Lei Orgânica do Tribunal de Contas da União e dá outras providências. Disponível em: <http://www2.camara.leg.br/legin/fed/lei/1992/lei8443-16-julho-1992-365298-norma-pl.html>. Acesso em: 20 mar. 2018.

. Lei no 9.478, de 6 de agosto de 1997 (Lei do Petróleo). Dispõe sobre a política energética nacional, as atividades relativas ao monopólio do petróleo, institui o Conselho Nacional de Política Energética e a Agência Nacional do Petróleo e dá outras providências. Disponível em: <http://www2.camara.leg.br/ legin/fed/lei/1997/lei-9478-6-agosto-1997-365401-norma-pl.html>. Acesso em: 20 mar. 2018.

Decreto no 3.735, de 24 de janeiro de 2001. Estabelece diretrizes aplicáveis às empresas estatais federais e dá outras providências. Disponível em: <http:// www2.camara.leg.br/legin/fed/decret/2001/decreto-3735-24-janeiro-2001357007-publicacaooriginal-1-pe.html>. Acesso em: 20 mar. 2018.

. Lei no 11.101, de 9 de fevereiro de 2005 (Lei de Falências). Regula a recuperação judicial, a extrajudicial e a falência do empresário e da sociedade empresária. Disponível em: <http://www2.camara.leg.br/legin/fed/lei/2005/lei11101-9-fevereiro-2005-535663-norma-pl.html>. Acesso em: 20 mar. 2018. 
Lei no 11.908, de 3 de março de 2009. Autoriza o Banco do Brasil S.A. e a Caixa Econômica Federal a constituírem subsidiárias e a adquirirem participação em instituições financeiras sediadas no Brasil; altera as Leis $n^{\text {os }} 7.940$, de 20 de dezembro de 1989, 10.637, de 30 de dezembro de 2002, 11.524, de 24 de setembro de 2007, e 11.774, de 17 de setembro de 2008; e dá outras providências. Disponível em: <http://www2.camara.leg.br/legin/fed/lei/2009/lei-11908-3-marco-2009586781-norma-pl.html>. Acesso em: 20 mar. 2018.

. Lei no 12.353 , de 28 de dezembro de 2010. Dispõe sobre a participação de empregados nos conselhos de administração das empresas públicas e sociedades de economia mista, suas subsidiárias e controladas e demais empresas em que a União, direta ou indiretamente, detenha a maioria do capital social com direito a voto e dá outras providências. Disponível em: <http://www.planalto.gov.br/ ccivil_03/_Ato2007-2010/2010/Lei/L12353.htm>. Acesso em: 20 mar. 2018.

. Lei no 12.490 , de 16 de setembro de 2011. Altera as Leis nos 9.478 , de 6 de agosto de 1997, e 9.847, de 26 de outubro de 1999, que dispõem sobre a política e a fiscalização das atividades relativas ao abastecimento nacional de combustíveis; o § 10 do art. 9o da Lei no 8.723, de 28 de outubro de 1993, que dispõe sobre a redução de emissão de poluentes por veículos automotores; as Leis nos 10.336, de 19 de dezembro de 2001, e 12.249, de 11 de junho de 2010; o Decreto- Lei no 509, de 20 de março de 1969, que dispõe sobre a transformação do Departamento dos Correios e Telégrafos em empresa pública; a Lei no 10.683, de 28 de maio de 2003, que dispõe sobre a organização da Presidência da República e dos Ministérios; revoga a Lei $n$ ㅇ 7.029, de 13 de setembro de 1982; e dá outras providências. Disponível em: <http://www2.camara.leg.br/legin/fed/lei/2011/lei-12490-16-setembro-2011611479-norma-pl.html>. Acesso em: 20 mar. 2018.

. Lei no 12.846, de 1 de agosto de 2013 (Lei Anticorrupção). Dispõe sobre a responsabilização administrativa e civil de pessoas jurídicas pela prática de atos contra a administração pública, nacional ou estrangeira, e dá outras providências. Disponível em: <http://www2.camara.leg.br/legin/fed/lei/2013/lei-12846-1agosto-2013-776664-norma-pl.html>. Acesso em: 20 mar. 2018.

. Lei no 13.303, de 30 de junho de 2016 (Lei de Responsabilidade das Estatais). Dispõe sobre o estatuto jurídico da empresa pública, da sociedade de economia mista e de suas subsidiárias, no âmbito da União, dos Estados, do Distrito Federal e dos Municípios. Disponível em: <http://www2.camara.leg.br/legin/fed/lei/2016/ lei-13303-30-junho-2016-783296-norma-pl.html>. Acesso em: 20 mar. 2018.

. Decreto no 8.945, de 27 de dezembro de 2016. Regulamenta, no âmbito da União, a Lei no 13.303, de 30 de junho de 2016, que dispõe sobre o estatuto jurídico da empresa pública, da sociedade de economia mista e de suas subsidiárias, no âmbito da União, dos Estados, do Distrito Federal e dos Municípios. Disponível em: <http://www2.camara.leg.br/legin/fed/decret/2016/decreto-8945-27-dezembro2016-784146-norma-pe.html>. Acesso em: 20 nov. 2017. 
Boletim das empresas estatais federais. Brasília, DF: Ministério do Planejamento, Desenvolvimento e Gestão, 2017. v. 5. Disponível em: <http:// www.planejamento.gov.br/assuntos/empresas-estatais/publicacoes/boletim-dasempresas-estatais>. Acesso em: 11 abr. 2018.

BüGE, M. et al. State-owned enterprises in the global economy: reason for concern? Vox: CEPR's Policy Portal, 2013. Disponível em: <https://voxeu.org/article/stateowned-enterprises-global-economy-reason-concern>. Acesso em: 10 abr. 2018.

CARNEY, M; GEDAJLOVIC, E; SUR, S. Corporate governance and stakeholder conflict. Journal of Management \& Governance, v.15, n. 3, p. 483-507, Aug. 2011.

Carvalho, A. G. Governança corporativa no Brasil em perspectiva. Revista de Administração, São Paulo, v. 37, n. 3, p. 19-31, jul./set. 2002.

DATAFolha. Privatização e preço dos combustíveis (PO 813942) em 29 e 30/11/2017.

Disponível em: <http://media.folha.uol.com.br/datafolha/2017/12/26/ c736e5a35b8eaae12c754dab7846f287.pdf>. Acesso em: 30 mar. 2018.

Dyck, A.; Zingales, L. Private benefits of control: an international comparison. Journal of Finance, v. 59, n. 2, p. 537-600, 2004.

ESTWICK, S. Principal-principal agency and financial flexibility in transition economies. Journal of Business Inquiry: Research, Education \& Application, v.15, n. 1, p. 33-54, jan. 2016.

FONTES FILHO, J. R.; PICOLIN, L. M. Governança corporativa em empresas estatais: avanços, propostas e limitações. Revista de Administração Pública, v. 42, n. 6, p. 1163-1188, nov./dez. 2008.

FrIEDMAN,. The social responsibility of business is to increase its profits. The New York Times Magazine, 13 set. 1970.

HILL, C.; JONES, T. M. Stakeholder-agency theory. Journal of Management Studies, v. 29, n. 2, p. 131-154, 1992.

Holland, Márcio. Uma proposta de metodologia para avaliação de conformidade legal. Seminário: a nova Lei das Estatais. Brasília, Tribunal de Contas da União, 29 de maio de 2017. Disponível em: <http://fgvprojetos.fgv.br/sites/fgvprojetos.fgv. br/files/arquivos/marcio_holland.pdf>. Acesso em: 10 nov. 2017.

INSTITUTO BRASILEIRO DE GOVERNANÇA CORPORATIVA (IBGC). Remuneração dos administradores 6a. ed. São Paulo, 2018. Disponível em: <http://conhecimento. ibgc.org.br/Lists/Publicacoes/Attachments/23483/Publicacao-IBGCPesquisaRemuneracao-6aEdicao.pdf>. Acesso em: 22 jan. 2018.

Jensen, M. C.; MeCKLING, W. H. Theory of the firm: managerial behavior, agency costs and ownership structure. Journal of Financial Economics, v. 3, n. 4, p. 305360, 1976.

JENSEN, M. C. Value maximization, Stakeholder Theory, and the corporate objective function. Journal of Applied Corporate Finance, v. 22, n. 1, p. 32-42, 2010.

JIANG, Y.; PENG, M. Principal-principal conflicts during crisis. Asia Pacific Journal of Management, v. 28, n. 4, p. 683-695, dec. 2011. 
KOPPELL, Jonathan GS. Pathologies of accountability: ICANN and the Challenge of "Multiple Accountabilities Disorder". Public Administration Review, v. 65, n. 1, p. 94-108, jan./feb. 2005.

LICHT, A. N. Corporate Governance. Encyclopedia of Financial Globalization (Gerard Caprio, Ed.). Elsevier: Oxford, 2011. Disponível em: <https://ssrn.com/ abstract=1786382>. Acesso em: 15 out. 2017.

LIMA, F. Nos últimos 2 anos, estatais custaram R\$ 40 bilhões à União. Folha de São Paulo, 09/01/2018. Disponível em: <http://www1.folha.uol.com.br/ mercado/2018/01/1949017-nos-ultimos-2-anos-estatais-custaram-r-40-bilhoes-auniao.shtml>. Acesso em: 22 mar. 2018.

MCKINSEY \& Company. McKinsey Investor Opinion Survey, junho 2000. Disponível em: $\quad<$ https://www.oecd.org/daf/ca/corporategovernanceprinciples/1922101. pdf>. Acesso em: 20 nov. 2017.

ORganisation for ECONOMIC COOPERATION AND DEVELOPMENT (OECD). Guidelines on corporate governance of state-owned enterprises, 2005. Disponível em: <http:// www.oecd.org/daf/ca/oecd-guidelines-corporate-governance-soes-2005.htm>. Acesso em 15 mar. 2018.

G20/OECD Principles of corporate governance. Paris: OECD Publishing, September 2015. Disponível em: <https://www.oecd.org/daf/ca/CorporateGovernance-Principles-ENG.pdf>. Acesso em: 14 nov. 2017.

. The size and sectoral distribution of State-owned enterprises. Paris: OECD Publishing, 2017. Disponível em: <http://dx.doi.org/10.1787/9789264280663-en> Acesso em: 10 jan. 2018.

PRZEWORSKI, Adam. Sobre o desenho do Estado: uma perspectiva agente x principal. In: Pereira, L. C. B; SPINK, P. K. (Org.). Reforma do Estado e administração pública gerencial. Rio de Janeiro: Editora FGV, 2003.

PwC. State-Owned Enterprises: Catalysts for public value creation? PwC, 2015. Disponível em: <https://www.pwc.com/gr/en/publications/assets/state-ownedenterprises-catalysts-for-public-value-creation.pdf>. Acesso em: 12 fev. 2018.

RING, P. S.; PERRY, J. Strategic management in public and private organizations: implications of distinctive contexts and constraints. Academy of Management Review, v. 10, n. 2, p. 276-286, 1985.

Rossı, G. A. S.; Dos SANTOS, W. J. L. Uma abordagem sobre a eficiência, eficácia e efetividade dos projetos e ações, de cunho social, ofertados pelo Poder Judiciário do Estado do Rio de Janeiro. Revista de Gestão Ambiental e Sustentabilidade, v. 5, n. 3, p. 152, 2016.

SHLEIFER, A.; VISHNY, R. W. A survey of corporate governance. Journal of Finance, v. 52, n. 2, p. 737-783, 1997.

SMITH, T. B. The policy implementation process. Policy sciences, v. 4, n. 2, p. 197209, 1973.

STOUT, L. The shareholder value myth: how putting shareholders first harms investors, corporations, and the public. San Francisco: Berrett-Koehler Publishers, 2012 
WARD, D; FIlatotcheV, I. Principal-principal-agency relationships and the role of external governance. Managerial \& Decision Economics. v. 31, n. 4, p. 249-261, jun. 2010.

YEUNG, R. L. K. Public enterprise governance: KCR corporation and its governance controversies. Public Management Review, v. 7, n. 4, p. 565-587, 2005.

YouNG, M. et al. Corporate governance in emerging economies: a review of the principal-principal perspective. Journal of Management Studies, v. 45, n. 1, p. 196220, 2008.

\section{Joaquim Rubens Fontes-Filho}

Doutor em Administração pela Fundação Getúlio Vargas (FGV). Atualmente é Professor Adjunto e Coordenador do Mestrado Executivo em Gestão Empresarial da Escola Brasileira de Administração Pública e de Empresas (FGV/ EBAPE).Contato: jorubens@globo.com 
RSP 